Assiut Scientific Nursing Journal

http://asnj.journals.ekb.eg

http://www.arabimpactfactor.com

\title{
Psychosomatic Disorders and Therapeutic Compliance Regarding Covid -19 Susceptible Patients: Intervention Study
}

\author{
Eman Ali Metwaly ${ }^{1} \&$ Bothina Elsayed Said Mohamed $^{2}$ \\ ${ }^{1 .}$ Lecturer of Medical Surgical Nursing Department, Faculty of Nursing, Zagazig University, Egypt \\ 2. Lecturer of Psychatric Nursing Department, Faculty of Nursing, Zagazig University, Egypt
}

\begin{abstract}
Background: The Spread of the COVID-19 disease has intensely affected the psychosomatic and physical wellbeing of the general population, including patients with chronic illness. The aim of this study: This study aimed to evaluate the effect of intervention study on psychosomatic disorders and therapeutic compliance regarding COVID19 susceptible patients. Design: Aquasi-experimental design was used in carrying out this study. Subjects: A purposeful sample of 30 COVID- 19 susceptible patients in pre-test, as well as the same sample in post-test was recruited for the study at Outpatients' clinics of chronic diseases in Zagazig University Hospitals. Seven tools were used in this study; A structured Interviewing Questionnaire for patients, Observational Checklists, Beck Anxiety Inventory Scale, Zung Self-Rating Depression Scale, Perceived Stress Scale, Athens Insomnia Scale, and Therapeutic Compliance Scale. Results: Statistically significant improvements were detected in patients' knowledge, practice, and therapeutic compliance post- intervention. There were statistically significant decreases of psychosomatic disorders as anxiety, depression, stress and insomnia for COVID-19 susceptible patients postintervention. Conclusions: Intervention study was effective in improving patients' knowledge which consequently reflected on improving their practices and therapeutic compliance. Also, these changes were effective in relieving psychosomatic disorders for COVID-19 susceptible patients. Recommendation: It is recommended that the developed illustrated booklet to be available for those patients in all health care settings.
\end{abstract}

\section{Keywords: COVID-19, Psychosomatic Disorders, Therapeutic Compliance \& Intervention Study}

\section{Introduction}

Patients with chronic illnesses are more at risk of the pandemic because the best way to fight COVID-19 is with a strong immune system. However, chronic diseases such as diabetes and kidney disease are immunosuppressed, making patients more susceptible to infection with treatment difficulties. While stress and anxiety are normal responses during crisis conditions, the negative effect of the COVID-19 outbreak may affect the clinical results of patients with chronic diseases such as mental disorders and cardiovascular illnesses whose prognosis and treatment are related to anxiety and stress (Kretchy, Asiedu-Danso \& Kretchy, 2020).

The COVID-19 pandemic has spread rapidly all over the world; the major mental health issue has increased the stress level of anxiety expressed in general mental health (Dong \& Bouey 2020). Insufficient knowledge about the incubation period of the virus, mode of transmission, its management, and protective measures cause fear and anxiety (Goyal, et al., 2020). The state of lockdown prevents populations from becoming residents of their homes, which leads to negative mental health results such as anxiety and insecurity toward the future. Individuals also feel monotonous, disappointed, and irritable when in lockdown (Ho, Chee \& Ho, 2020).

Patients with confirmed or suspected COVID-19 may experience fear of the consequences of infection with a possibly fatal new virus, and people in the quarantine may experience boredom, loneliness, and psychiatric illnesses such as insistent depression, anxiety, and panic attacks. Moreover, symptoms of infection, side effects of management, like insomnia caused by corticosteroids, can worsen anxiety and mental distress (Silva et al., 2019). However, patients with the chronic physical disease also require regular follow-up in hospitals which becomes a problem and increase the probabilities of worsening (Kar et al., 2020).

Personal protective equipment (PPE) such as face masks help to prevent the spread of respiratory infections as COVID-19. Face masks not only protect against infectious aerosols but also prevent the spread of disease to vulnerable individuals while traveling through public transportation systems (Liu \& Zhang, 2020). Another important practice that can decrease the transmission of respiratory illnesses is keeping hands clean. Hand hygiene will only decrease the spread of the disease if the virus is transmitted through the formation of large droplets (Lai et al., 2020). 
Nursing is one of the most important professions specialized in preventing disease and alleviating suffering during and after treatment of any disease, including COVID-19 (WHO, 2020). However, Nurses play a major role in reassuring the patient during the various stages of the disease. With the changing symptoms of the COVID-19, patients were found to be fearful and need continuous support and assurance. Besides, Covid-19 patients may progress strong feelings and psychological trauma. Nurses can experience that through the level of sadness and anxiety. COVID-19 patients have a lot of causes for panic, especially when they are isolated from those they love, along with worrying about their livings. Therefore, the nurses play a role in calming the patients and mitigating uncertainty, misinformation, and complete information about risks of disease (Buheji \& Buhaid, 2020).

\section{Significant of the study:}

According to the Public Health Agency of Canada, some people are at a greater risk of developing a more serious disease or complications from COVID-19. Although most people with COVID-19 recover, chronically ill people are also more likely to mortality if they become ill (Li et al., 2020). The best way for those patients to protect themselves from COVID-19 is protective self-isolation and keeping body distance, remaining away from patients (Brooks et al., 2020). For example, those patients need optimal compliance with their medications, diet, and exercise to ensure higher immunity, viral suppression, and management success, despite stress, anxiety, depression, and decrease the risk of infection (Huang, \& Zhao, 2020a). Therefore, the current study was carried out to evaluate the effect of intervention study on psychosomatic disorders and therapeutic compliance regarding COVID-19 susceptible patients.

\footnotetext{
Aim of the Study

This study aimed to evaluate the effect of intervention study on psychosomatic disorders and therapeutic compliance regarding COVID-19 susceptible patients.

Objectives:

- Assess knowledge and practice for COVID-19 susceptible patients

- Assess psychosomatic disorders for COVID-19 susceptible patients.

- Assess therapeutic compliance for COVID-19 susceptible patients.

- Design, implement, and evaluate the effect of intervention study on psychosomatic disorders and therapeutic compliance regarding COVID-19 susceptible patients.
}

Research hypotheses:

- Mean scores of patients' knowledge and practice will increase after the intervention study.

- Psychosomatic disorders for patients will improve after the intervention study.

- Therapeutic compliance for patients will improve after the intervention study.

\section{Materials and Methods \\ Research Design:}

A quasi experimental design was used to achieve the aim of the study through Pre/post-test.

\section{Study Setting:}

The study was conducted at outpatients' clinics of chronic diseases in Zagazig University Hospitals, Egypt.

Study Subjects:

A purposeful sample of (30) COVID- 19 susceptible patients in pre-test as well as the same sample in posttest were recruited for this study. The sample was calculated by power and sample size, using Epi Info (Epidemiological Information system) Software Version 6. The data collected had a confidence level of $95 \%$, and the power of the study was $80 \%$. Patients were recruited according to the following inclusion criteria; Age of patients between 30-65 years, and patients with chronic diseases as diabetes mellitus and hypertension. Exclusion criteria: include patients with end stage diseases, psychiatric and neurological disorders, and unable to communicate.

\section{Tools of Data Collection:}

Seven tools were used in this study as follows:

Tool I: A structured Interviewing Questionnaire for patients: Designed by the researchers after reviewing related literature, it was written in Arabic and covered two parts:

Part 1: Demographic characteristics: e.g., age, sex, marital status, education, job etc...

Part 2: Questions to assess patient's knowledge (Pre/Post-test): they included questions about COVID- 19 definition, symptoms, mode of transmission, diagnosis, treatment and quarantine or self-isolation. Scoring: Each question scored "zero" for the incorrect answer or don't know and "one" for the correct answer. The general patient's knowledge was classified into satisfactory if the score $\geq 60 \%$ from the maximum score or unsatisfactory knowledge if it is $<60 \%$.

Tool II: Observational Checklists (Pre/Post-test): Adapted from (Aiello et al., 2012), to assess patient's practice regarding infection control methods. It included three checklists about: Hand washing technique: (10 items), steps of wearing and removing the mask (nine items), and gloves (13 items). Scoring: the items observed "done" were scored one and "not done" zero. The practice was considered adequate if 
the percent score was $60 \%$ or more and inadequate if less than $60 \%$.

Tool III: Beck Anxiety Inventory (BAI) Scale (Pre/Post-test): Was constructed by (KheshtMasjedi, et al., 2015) to measure anxious symptomatology in adults. It is composed of 23 items with a 4-point Likert scale response: "not at all," "mildly," "moderately," and "severely", which were scored $0,1,2$, and 3 respectively.

Tool IV: Zung Self-Rating Depression Scale (SDS) (Pre/Posttest): It was designed by (Zung, 2010) to assess the level of depression. The total number of items of the scale were 20. Scoring: Each item was scored 1-4 (a little time, sometimes, good part of the time, most time respectively).

Tool V: The Perceived Stress Scale (PSS) (Pre/Posttest): It was developed by (Chaaya et al., 2010) to measure the perception of stress. The total items of the scale were 10. Scoring: each item was scored 0-4 (Never, Almost Never, Sometimes, Often, and Very often respectively).

Tool VI: Athens Insomnia Scale (AIS) (Pre/Posttest): It was developed by (Paparrigopoulos et al., 2010) for assessing insomnia during the last month. It consisted of eight items. Scoring: Each item was rated from zero to 3. Patients were asked to grade the severity of these complaints (absent $=0$, mild $=1$, severe $=2$, and very severe $=3$ ). A total score of 6 points or higher was considered as a positive case for insomnia.

Tool VII: Patient Compliance with Therapeutic Regimen Scale (Pre/Post-test): Adopted from (Chatziefstratiou et al., 2019), it consisted of three parts about dietary, therapeutic, and life style modification (smoking, exercise...etc). Scoring: every item answered by never $=0$, sometime $=1$ and always $=2$. The compliance was considered adequate if the percent score was $60 \%$ or more and inadequate if less than $60 \%$.

\section{Content validity and Reliability:}

Content validity of the tools were evaluated by a panel of five experts from academic staff at the Faculty of Nursing, and Faculty of Medicine, Zagazig University, who revised the tools for clarity, applicability, relevance, comprehensiveness, and ease for implementation. The reliability of the tools was assessed by Cronbach's alpha test. The level of reliability was $\mathrm{r}=0.95$.

Pilot study:

A pilot study was conducted with the assistance of three patients (10\% of the sample), selected randomly to ensure the clarity and understanding of the items as presented and to estimate the time needed to fill in the tools. Data obtained from the piloted patients were included in the study because of no required modifications.

\section{Ethical considerations:}

Permission for the study was obtained from the Research Ethics Committee at the Faculty of Nursing, Zagazig University on $10^{\text {th }}$ March, 2020 and from the Medical Manager of Zagazig University Hospital before conducting the intervention. The patients were informed that their sharing in the study was voluntary; anonymity and confidentiality of the data were assured. They were informed about their right to withdraw from the study at any phase without penalty. Consent was established by the end of filling in the questionnaire.

Field Work:

The study lasted six months started from the beginning of April 2020 to the end of September 2020.

Assessment phase: Upon finalization of the tools and securing necessary official permissions, the researchers started to recruit the participants according to the eligibility criteria. First, they introduced themselves, explained the purpose of the study briefly to the patients, and invited them to participate. Every patient was met individually and oral consent for participation was obtained. The researchers read and explained the tools' items to the patient and then asked him/her the form to fill in the answers. The time consumed for answering all questions and scales ranged from 30 to 35 minutes. This phase lasted one month April 2020.

Planning phase: Based on the results obtained from the assessment phase, and because of related literature, the researchers designed the intervention sessions. The objectives and content were according to the patients' needs which were covered in a booklet. This booklet was prepared in simple Arabic language.

Implementation phase: Data were collected outpatient's clinic of chronic diseases at Zagazig University hospitals, Egypt. This intervention was covered by 18 sessions actualized in the form of small group sessions (4-5 patients in each session). Each session possess a title and objective. The length of each session was distinctive according to patients' assimilation of content, which changed agreeing to their educational level, reaction, time accessibility and content of each session. The time of the theoretical session was 30-40 minutes and the practical session 40-45 minutes. The intervention consisted of two main parts. First, the theoretical part (eight sessions) about definition of COVID-19, symptoms, susceptible patients, diagnosis, treatment, modes of transmission, and infection control methods, instructions for patients who come in contact with infectious patients, instructions about quarantine or self-isolation, guidelines for self-isolated patients, precautions to prevent infection with COVID- 19, 
vaccine for COVID- 19, WHO guidelines to prevent infection. Also, it included instructions about diet, exercise, management of anxiety, stress, insomnia, depression, and sleep disorders, in addition to strategies for patient's compliance and factors affecting it. Second, the Practical part (ten sessions) about hand washing technique, correct steps of wearing and removing the mask, and gloves, deep breathing exercise, and muscle relaxation techniques for all body muscle, and mental relaxation as meditation and the imagination. The intervention implemented through presentation, videos, role play, and group discussion. This phase covered a period of four months from the beginning of May 2020 to the end of August 2020.

Evaluation phase: The evaluation (post- test) was undertaken immediately post- intervention by using the same data collection tools to evaluate the effect of intervention study on psychosomatic disorders and therapeutic compliance for studied patients. This phase lasted one month September 2020.

\section{Statistical analysis:}

Data were collected, coded, entered and analysed using Microsoft Excel software. Data were then imported into Statistical Package for the Social Sciences (SPSS, IBM, USA) version 20.0 for analysis. According to the type of data qualitative variables were represented as number and percentage, quantitative continues group was represented by mean $\pm \mathrm{SD}$, the following tests were used to test differences for significance; Difference and association of qualitative variable by Chi-square test $\left(\mathrm{X}^{2}\right)$ paired by sign or Mac Nemar. Differences between quantitative paired groups by paired t-test, correlation by Pearson's correlation. P-value was set at $<0.05$ for significant results and $<0.001$ for highly significant results.

\section{Results}

Table (1): Frequency Distribution of Socio- demographic Characteristics for Studied Patients $(\mathbf{n}=\mathbf{3 0})$

\begin{tabular}{|c|c|c|c|}
\hline \multicolumn{2}{|c|}{ Socio- demographic characteristics } & No & $\%$ \\
\hline \multirow{2}{*}{\multicolumn{2}{|c|}{ Age }} & 8 & 26.7 \\
\hline & & 22 & 73.3 \\
\hline \multicolumn{2}{|c|}{$\frac{\geq 50}{\text { Mean } \pm \text { SD }}$} & \multicolumn{2}{|c|}{$54.2 \pm 8.47$} \\
\hline \multicolumn{2}{|c|}{ Median (Range) } & \multicolumn{2}{|c|}{$56.0(34-65)$} \\
\hline \multirow[t]{2}{*}{ Sex } & Male & 15 & 50.0 \\
\hline & Female & 15 & 50.0 \\
\hline \multirow[t]{2}{*}{ Marital status } & Married & 20 & 66.7 \\
\hline & Not married & 10 & 33.3 \\
\hline \multirow[t]{2}{*}{ Educational level } & Educated & 23 & 76.7 \\
\hline & Not educated & 7 & 23.3 \\
\hline \multirow[t]{2}{*}{ Occupation } & Working & 15 & 50.0 \\
\hline & Not working & 15 & 50.0 \\
\hline \multirow[t]{2}{*}{ Residence } & Rural & 19 & 63.3 \\
\hline & Urban & 11 & 36.7 \\
\hline \multirow[t]{3}{*}{ Income } & Sufficient & 20 & 66.7 \\
\hline & Insufficient & 8 & 26.7 \\
\hline & Sufficient \& Save & 2 & 6.7 \\
\hline \multirow[t]{2}{*}{ Comorbidities } & Hypertension & 11 & 36.7 \\
\hline & Diabetes Mellitus & 19 & 63.3 \\
\hline \multirow[t]{2}{*}{ Exercise } & Yes & 3 & 10.0 \\
\hline & No & 27 & 90.0 \\
\hline \multirow[t]{2}{*}{ Social status } & Low & 12 & 40.0 \\
\hline & Moderate & 14 & 46.7 \\
\hline \multirow{2}{*}{ Total } & High & 4 & 13.3 \\
\hline & & 30 & 100.0 \\
\hline
\end{tabular}


Table (2): Mean Score of Patients' Knowledge, Practice, and Compliance Pre/Post Intervention $(\mathbf{n}=\mathbf{3 0})$

\begin{tabular}{|c|c|c|c|c|c|}
\hline Items & Time & Mean & SD & Paired t-test & P-value \\
\hline \multirow{2}{*}{ Total Knowledge } & Pre & 1.83 & 1.05 & \multirow[t]{2}{*}{-16.76} & \multirow[t]{2}{*}{$0.00^{* *}$} \\
\hline & Post & 7.30 & 1.44 & & \\
\hline \multirow{2}{*}{$\begin{array}{l}\text { Practice } \\
\text { Hand washing }\end{array}$} & Pre & 5.00 & 1.43 & \multirow[t]{2}{*}{-7.30} & \multirow[t]{2}{*}{$0.00 * *$} \\
\hline & Post & 7.30 & .95 & & \\
\hline \multirow{2}{*}{$\begin{array}{l}\text { Wearing and removing the } \\
\text { mask }\end{array}$} & Pre & 3.73 & 1.04 & \multirow[t]{2}{*}{-10.07} & \multirow[t]{2}{*}{$0.00^{* * *}$} \\
\hline & Post & 7.43 & 1.71 & & \\
\hline \multirow{2}{*}{$\begin{array}{lll}\begin{array}{l}\text { Wearing } \\
\text { gloves }\end{array} & \text { and } & \text { removing } \\
\end{array}$} & Pre & 6.13 & 1.47 & \multirow[t]{2}{*}{-8.50} & \multirow{2}{*}{$0.00^{* *}$} \\
\hline & Post & 9.76 & 1.81 & & \\
\hline \multirow{2}{*}{ Total Practice } & Pre & 14.90 & 2.41 & \multirow[t]{2}{*}{-12.97} & \multirow[t]{2}{*}{$0.00^{* *}$} \\
\hline & Post & 24.43 & 3.22 & & \\
\hline \multirow{2}{*}{$\begin{array}{l}\text { Compliance } \\
\text { Dietary compliance }\end{array}$} & Pre & 3.36 & 1.62 & \multirow[t]{2}{*}{-19.69} & \multirow{2}{*}{$0.00^{* *}$} \\
\hline & Post & 10.26 & 1.01 & & \\
\hline \multirow[t]{2}{*}{ Therapeutic compliance } & Pre & 5.56 & 2.29 & \multirow[t]{2}{*}{-16.83} & \multirow[t]{2}{*}{$0.00 * *$} \\
\hline & Post & 14.53 & 1.79 & & \\
\hline \multirow[t]{2}{*}{ Life style modification } & Pre & 3.00 & 2.42 & \multirow[t]{2}{*}{-10.30} & \multirow[t]{2}{*}{0.00 ** } \\
\hline & Post & 10.03 & 2.84 & & \\
\hline \multirow{2}{*}{ Total compliance } & Pre & 11.93 & 3.44 & \multirow[t]{2}{*}{-23.03} & \multirow[t]{2}{*}{$0.00 * *$} \\
\hline & Post & 34.83 & 4.21 & & \\
\hline
\end{tabular}

** Highly Significant $(P<0.001)$

Table (3): Mean Score of Anxiety, Depression, Stress and Insomnia Pre/ Post Intervention (n=30)

\begin{tabular}{|c|c|c|c|c|c|}
\hline Scale & Time & Mean & $\overline{\text { SD }}$ & $\begin{array}{c}\text { Paired } \\
\text { t-test }\end{array}$ & $\overline{\text { P-value }}$ \\
\hline \multirow[t]{2}{*}{ Anxiety } & Pre & 44.50 & 12.72 & \multirow{2}{*}{12.49} & \multirow{2}{*}{$0.00 * *$} \\
\hline & Post & 12.40 & 6.00 & & \\
\hline \multirow[t]{2}{*}{ Depression } & Pre & 61.10 & 5.17 & \multirow{2}{*}{13.70} & \multirow{2}{*}{$0.00 * *$} \\
\hline & Post & 36.70 & 8.26 & & \\
\hline \multirow[t]{2}{*}{ Stress } & Pre & 28.73 & 5.48 & \multirow{2}{*}{10.92} & \multirow{2}{*}{$0.00 * *$} \\
\hline & Post & 12.83 & 5.78 & & \\
\hline \multirow[t]{2}{*}{ Insomnia } & Pre & 12.83 & 3.53 & \multirow{2}{*}{12.18} & \multirow{2}{*}{$0.00 * *$} \\
\hline & Post & 3.43 & 2.31 & & \\
\hline
\end{tabular}

** Highly Significant $(P<0.001)$

Table (4): Relations between Knowledge, Compliance and Practice Pre/Post Intervention (n=30)

\begin{tabular}{|c|c|c|c|c|c|c|}
\hline \multicolumn{3}{|c|}{ Items } & \multicolumn{2}{|c|}{ Time } & \multirow{3}{*}{$\begin{array}{c}\text { Total } \\
34 \\
\end{array}$} & \multirow[t]{3}{*}{ P-value } \\
\hline & & & Pre & Post & & \\
\hline \multirow[t]{4}{*}{ Knowledge } & \multirow{2}{*}{ Unsatisfactory $<60 \%$} & No & 30 & 4 & & \\
\hline & & $\%$ & $100.0 \%$ & $13.3 \%$ & $56.7 \%$ & \\
\hline & \multirow[t]{2}{*}{ Satisfactory $\geq 60 \%$} & No & 0 & 26 & 26 & $0.00^{* * *}$ \\
\hline & & $\%$ & $0.0 \%$ & $86.7 \%$ & $43.3 \%$ & \\
\hline \multirow[t]{4}{*}{ Compliance } & \multirow{2}{*}{ Inadequate $<60 \%$} & No & 20 & 0 & 20 & \\
\hline & & $\%$ & $66.7 \%$ & $0.0 \%$ & $33.3 \%$ & \\
\hline & \multirow[t]{2}{*}{ Adequate $\geq 60 \%$} & No & 10 & 30 & 40 & $0.00^{* * *}$ \\
\hline & & $\%$ & $33.3 \%$ & $100.0 \%$ & $66.7 \%$ & \\
\hline \multirow[t]{4}{*}{ Practice } & \multirow[t]{2}{*}{ Inadequate $<60 \%$} & No & 27 & 2 & 29 & \\
\hline & & $\%$ & $90.0 \%$ & $6.7 \%$ & $48.3 \%$ & \\
\hline & \multirow[t]{2}{*}{ Adequate $\geq 60 \%$} & No & 3 & 28 & 31 & $0.00^{* * *}$ \\
\hline & & $\%$ & $10.0 \%$ & $93.3 \%$ & $51.7 \%$ & \\
\hline
\end{tabular}

** Highly Significant $(P<0.00)$ 
Table (5): Relations between Patients' Knowledge and their Demographic Characteristics (n=30)

\begin{tabular}{|c|c|c|c|c|c|c|}
\hline \multirow{2}{*}{\multicolumn{3}{|c|}{ Items }} & \multirow{2}{*}{\multicolumn{2}{|c|}{ Knowledge }} & \multirow[t]{3}{*}{$\mathbf{X}^{2}$} & \multirow[t]{3}{*}{$\mathbf{P}$} \\
\hline & & & & & & \\
\hline \multirow{4}{*}{ Sex } & \multirow{2}{*}{ Male } & No & 0 & 15 & & \\
\hline & & $\%$ & $0.0 \%$ & $100.0 \%$ & & \\
\hline & \multirow{2}{*}{ Female } & No & 4 & 11 & 4.61 & $0.032 *$ \\
\hline & & $\%$ & $26.7 \%$ & $73.3 \%$ & & \\
\hline \multirow{4}{*}{ Marital status } & \multirow{2}{*}{ Married } & No & 0 & 20 & & \\
\hline & & $\%$ & $0.0 \%$ & $100.0 \%$ & & \\
\hline & \multirow{2}{*}{ Not married } & No & 4 & 6 & 9.23 & $0.002 *$ \\
\hline & & $\%$ & $40.0 \%$ & $60.0 \%$ & & \\
\hline \multirow{4}{*}{$\begin{array}{l}\text { Educational } \\
\text { level }\end{array}$} & \multirow{2}{*}{ Educated } & No & 0 & 23 & & \\
\hline & & $\%$ & $0.0 \%$ & $100.0 \%$ & & \\
\hline & \multirow{2}{*}{ Not educated } & No & 4 & 3 & 15.16 & $0.00^{* *}$ \\
\hline & & $\%$ & $57.1 \%$ & $42.9 \%$ & & \\
\hline \multirow{4}{*}{ Occupation } & \multirow{2}{*}{ Working } & No & 0 & 15 & & \\
\hline & & $\%$ & $0.0 \%$ & $100.0 \%$ & & \\
\hline & \multirow{2}{*}{ Not working } & No & 4 & 11 & 12.69 & $0.002 *$ \\
\hline & & $\%$ & $0.0 \%$ & $100.0 \%$ & & \\
\hline \multirow{6}{*}{ Income } & \multirow{2}{*}{ Sufficient } & No & 0 & 20 & & \\
\hline & & $\%$ & $0.0 \%$ & $100.0 \%$ & & \\
\hline & \multirow{2}{*}{ Insufficient } & No & 4 & 4 & 12.69 & $0.002 *$ \\
\hline & & $\%$ & $50.0 \%$ & $50.0 \%$ & & \\
\hline & \multirow{2}{*}{ Enough \& Save } & No & 0 & 2 & & \\
\hline & & $\%$ & $0.0 \%$ & $100.0 \%$ & & \\
\hline \multirow{6}{*}{ Social status } & \multirow{2}{*}{ Low } & No & 4 & 8 & & \\
\hline & & $\%$ & $33.3 \%$ & $66.7 \%$ & & \\
\hline & \multirow{2}{*}{ Moderate } & No & 0 & 14 & 6.92 & $0.031 *$ \\
\hline & & $\%$ & $0.0 \%$ & $100.0 \%$ & & \\
\hline & \multirow{2}{*}{ High } & No & 0 & 4 & & \\
\hline & & $\%$ & $0.0 \%$ & $100.0 \%$ & & \\
\hline \multirow{2}{*}{\multicolumn{2}{|c|}{ Total }} & No & 4 & 26 & & \\
\hline & & $\%$ & $13.3 \%$ & $86.7 \%$ & & \\
\hline
\end{tabular}

Table (6): Correlations between Different Study Variables Pre/Post Intervention $(n=30)$

\begin{tabular}{|c|c|c|c|c|}
\hline & & Total knowledge & Total compliance & $\begin{array}{c}\text { Total } \\
\text { practice }\end{array}$ \\
\hline \multirow[t]{2}{*}{ Knowledge } & $\mathrm{R}$ & 1 & $0.89^{\cdots+}$ & 0.81 \\
\hline & $\mathrm{P}$ & - & 0.00 & 0.00 \\
\hline \multirow[t]{2}{*}{ Anxiety } & $\mathrm{R}$ & $-0.79^{* *}$ & $-0.84^{* \pi}$ & $-.73^{* \pi}$ \\
\hline & $\mathrm{P}$ & 0.00 & 0.00 & 0.00 \\
\hline \multirow{2}{*}{ Depression } & $\mathrm{R}$ & $-0.79^{* n}$ & $-0.85^{n-1}$ & $-0.76^{\pi}$ \\
\hline & $\mathrm{P}$ & 0.00 & 0.00 & 0.00 \\
\hline \multirow[t]{2}{*}{ Stress } & $\mathrm{R}$ & $-0.73^{\prime \prime}$ & $-0.85^{*}$ & $-0.68^{* 1}$ \\
\hline & $\mathrm{P}$ & 0.00 & 0.00 & 0.00 \\
\hline \multirow[t]{2}{*}{ Insomnia } & $\mathrm{R}$ & $-0.76^{\prime \prime}$ & $-0.84^{m+n}$ & $-0.67^{*}$ \\
\hline & $\mathrm{P}$ & 0.00 & 0.00 & 0.00 \\
\hline \multirow[t]{2}{*}{ Compliance } & $\mathrm{R}$ & $0.89^{\text {nN }}$ & 1 & 0.80 \\
\hline & $\mathrm{P}$ & 0.00 & - & 0.00 \\
\hline \multirow[t]{2}{*}{ Practice } & $\mathrm{R}$ & $0.81^{\prime \prime}$ & $0.80^{\prime \prime}$ & 1 \\
\hline & $\mathrm{P}$ & 0.00 & 0.00 & - \\
\hline
\end{tabular}

Table (1): Reveals that $73.3 \%$ of studied patients was aged 50 years or more with a mean \pm SD of $54.2 \pm 8.47$, male and female were matched, with $66.7 \%$ of them were married while $76.7 \%$ educated, and $50.0 \%$ working. As well, $63.3 \%$ of them reside in rural areas, with $66.7 \%$ of them had sufficient income. As regards 
comorbidities $63.3 \%$ were diabetic and $36.7 \%$ were hypertensive. However, only $10 \%$ did exercise and regarding social status, moderate was the highest, followed by low $(46.7 \%$ \& $40.0 \%$ respectively).

Table (2): Shows a highly statistically significant increase in score of patients' knowledge, practice, and compliance post -intervention than before $(\mathrm{p}=0.00)$.

Table (3): Demonstrates highly statistically significant decreases of all mean scores regarding to anxiety, depression, stress and insomnia post intervention than before $(\mathrm{p}=0.00)$.

Table (4): Clarifies statistically significant relations between patients' knowledge about COVID- 19, practice and compliance post-intervention than before $(\mathrm{p}=0.00)$.

Table (5): Clears statistically significant relations between patients' knowledge and sex $(p=0.032)$, marital status $(p=0.002)$, occupation $(p=0.002)$, income $(\mathrm{p}=0.002)$, and social status $(\mathrm{p}=0.031)$. However, the relation with educational level was the only highly significant one $\left(\mathrm{x}^{2}=15.16, \mathrm{p}=0.00\right)$.

Table (6): Reveals that, strong positive correlations were found between patients' total knowledge and total compliance, and total practice. As well, strong negative correlations were found between anxiety and total patients' knowledge, total compliance, and total practice. Moreover, strong negative correlations were found between depression, patients' knowledge, compliance, and practice. However, strong negative correlations were found between stress and total patients' knowledge, total compliance, and total practice. Also, there were strong negative correlations between insomnia and total patients' knowledge, total compliance, and total practice with highly statistically significant differences between all variables $(\mathrm{P}=$ 0.000).

\section{Discussion}

As regards socio- demographic data of the study patients, the results revealed that about three quarter of them their age was 50 years or more with a mean \pm SD of $54.2 \pm 8.47$, both genders were matched, with two third of them were married. More than three quarters of them was educated and half of them were working. Near two third of them reside in rural areas, with two third of them had sufficient income. Considering comorbidities, about two third of them were diabetic and one third were hypertensive, however, only $10 \%$ were practicing exercises.

The current study finding is to some extent in the same line with those of Abdelhafiz et al. (2020) who stated that more than half $(52.2 \%)$ were university graduates and $27.0 \%$ of the subjects had a history of one or more chronic diseases. Similarly, Labban et al. (2020) found that for $52.5 \%$ of patients their age ranged from 35 to 50 years and $72.75 \%$ were college graduates.

After the implementation of the current intervention study, there was a highly statistically significant increase in patients' knowledge about COVID- 19. This finding could reflect the widespread mass media exposure of the disease and the government's reactions during the pandemic. This previous result was in congruence with that of Zaid et al. (2020) who found that all population in Jordan appears to have satisfactory information about COVID-19. Similarly, the previous results were in accordance with Labban et al. (2020) who stated that most of their study subjects showed generally moderate knowledge about COVID 19.

Regarding patients' practice, there were statistically significant improvements of patients' practice scores through hand washing, wearing and removing masks and gloves post- intervention. This may be due to that more than three quarters of the study patients were educated, which helped them to gain knowledge through social media, the internet, media channels, and following the precautionary guidelines and protective measures to limit the spread of the disease. Furthermore, the adequate level of patients' knowledge about COVID-19 reflected then on their practice, as there was a strong positive correlation between knowledge and practice of studied patients.

This previous finding was in congruence with that of Geldsetzer (2020) who stated that most of the contributors in both the United States and the United Kingdom believed that washing hands, avoiding close contact with patients, and avoiding touching eyes, nose, and mouth with unwashed hands were effective in preventing infection with the COVID-19 virus. In the same line, Saqlain et al. (2020) reported that, all of their subjects responded to all six items related to COVID-19 practice with the highest seen regarding hand washing (94\%), and a similar percentage (93.8\%) revealed that they avoid crowded places. However, a lower percentage of good practice was observed among the entire population for wearing face masks $(79.8 \%)$.

The findings of the present study revealed highly statistically significant increases in patients' compliance regarding diet, therapy, and life style modification post- intervention. This could be explained by the fact that persons with certain chronic illnesses or weakened immunity are facing greater risks than healthy ones regarding probability novel coronavirus infection. Therefore, those patients comply with their medication, diet and life style modification to prevent catching an infection.

This study finding was supported by those of Jiménez-Pavón et al. (2020) which revealed that despite the quarantine period is the best choice and 
recommendation to stop the spread of infections quickly, the sudden onset of quarantine state means a drastic change in the lifestyle of the residents. These lifestyles and behaviors include a certain level of physical activity, exercise, and a healthy diet to maintain a proper state of health, to counter the negative effects of some diseases, such as diabetes, high blood pressure and respiratory diseases. As well, the previous finding was in congruence with that of Cross et al. (2020) who indicated that the mean adherence score in the intervention group was greater than in the typical care group.

The current study result showed an increase of anxiety, depression, stress, and insomnia preintervention. This might be due to patients' feeling of responsibility toward their families. They tended to worry about the health of their family members rather than themselves. This result agreed with that of $\mathbf{F u}$ et al. (2020) who found that more than a quarter of the population suffered from mental disorders, such as anxiety and depression, and about a third of them suffered from sleep disorders. In the same line, Wang et al. (2020) found that $53.8 \%$ of participants rated the psychological effect of the outbreak as moderate or severe; $16.5 \%$ specified symptoms of depression, $28.8 \%$ reported symptoms of anxiety, and $8.1 \%$ found they had levels of stress.

Meanwhile, the implementation of the current study intervention was significantly successful in decreasing the levels of anxiety, depression, stress and insomnia among the study patients. This means that effective interventions can prevent the further development of psychological problems.

The study finding summarized statistically significant relations between patients' knowledge about corona virus, practice and their compliance. This result was in the same line with that of Reuben et al. (2020), who found that participated Nigerians have good knowledge about COVID-19 with positive attitudes and compliance with the infection prevention and control measures set by the government, which are essential for reducing the spread of corona virus.

A statistically significant relation was found between satisfactory knowledge and the educational level of studied patients. This relation may reverse their source of information about the disease and how they understood it. In addition, the level of education is positively related to increased awareness and compliance with the prevention and control of the COVID-19 epidemic. This was in the same line with that of Isah et al. (2020) who found a significant correlation between the knowledge score of the subjects and their educational level. Similarly, the previous finding was congruent with that of $\mathrm{Al}$ Hanawi et al. (2020) who found a positive correlation between knowledge, education, and age.
The study finding revealed strong negative correlations detected between anxiety, depression, stress and insomnia and patients' knowledge, compliance, and practice. In agreement with the previous finding, Huang \& Zhao (2020b) suggested that all societies across China require urgent psychological intervention. In addition, the psychological counselors should meet the basic needs of patients with psychological conditions and provide positive information about epidemic prevention, in order to inhibit the incidence of psychosomatic problems.

Finally, the current study results revealed that significant negative correlations were detected between anxiety, depression, stress and insomnia with patients' practices as regards hand washing technique, mask and gloves techniques. This result agreed with that of Fu et al. (2020), which revealed that preventive measures (e.g., hand washing, wearing a mask) were also related with lower psychosomatic effect of the outbreak and lower levels of anxiety, stress, and depression.

\section{Conclusion}

The intervention study was effective in improving patients' knowledge which consequently reflected on improving their practices and therapeutic compliance. In addition, these changes were effective in relieving psychosomatic disorders for COVID-19 susceptible patients.

\section{Recommendation}

- It is recommended that the developed illustrated booklet be available for those patients in all health care settings.

- The intervention study should be replicated on a larger sample of the population to give stronger evidence of its important findings.

\section{References}

- Abdelhafiz, A., Mohammed, Z., Ibrahim, M., Ziady, H., Alorabi, M., Ayyad, M., \& Sultan, E. (2020): Knowledge, perceptions, and attitude of Egyptians towards the novel coronavirus disease (COVID-19). Journal of Community Health, 1-10.

- Aiello, A.E., Perez, V., Coulborn, R.M., Davis, B.M., Uddin, M. \& Monto, A.S. (2012): Facemasks, hand hygiene, and influenza among young adults: a randomized intervention trial. PloS one, 7(1): e29744.

- Al-Hanawi, M., Angawi, K., Alshareef, N., Qattan, A., Helmy, H., Abudawood, Y., Alqurashi, M., Kattan, W., Kadasah, N., Chirwa, G., \& Alsharqi, O. (2020): Knowledge, attitude and practice toward covid-19 
among the public in the Kingdom of Saudi Arabia: A Cross-Sectional Study. Frontiers in Public Health, 8.

https://doi.org/10.3389/fpubh.2020.00217.

- Brooks, S., Webster, R., Smith, L., Woodland, L., Wessely, S., Greenberg, N., \& Rubin, G. (2020): The psychological impact of quarantine and how to reduce it: rapid review of the evidence. The Lancet. 395/10227, 912-920. https://doi.org/10.1016/S0140-6736(20)30460-8.

- Buheji, M., \& Buhaid, N. (2020): Nursing Human Factor during COVID-19 Pandemic. International Journal of Nursing Science, 10(1): 12-24. DOI:10.5923/j.nursing.20201001.02.

- Chaaya, M., Osman, H., Naassan, G. \& Mahfoud, Z. (2010): Validation of the Arabic version of the Cohen perceived stress scale (PSS10) among pregnant and postpartum women. BMC Psychiatry, 10 (111).

- Chatziefstratiou, A., Giakoumidakis, K., Fotos, N., Baltopoulos, G. \& Brokalaki, H. (2019): Scales for assessing medication adherence in patients with hypertension. British Journal of Nursing, 28(21):1388-1392.

- Cross, A., Elliott, R., Petrie, K., Kuruvilla, L., \& George, J. (2020): Interventions for improving medication-taking ability and adherence in older adults prescribed multiple medications. Cochrane Database of Systematic Reviews, (5). https://doi.org/10.1002/14651858.CD012419.pub2

- Dong, L., \& Bouey, J. (2020): Public mental health crisis during COVID-19 pandemic, China. Emerg Infect Dis, 26(7), 10-3201. http://doi.org/10.3201/eid2607.200407.

- Fu, W., Wang, C., Zou, L., Guo, Y., Lu, Z., Yan, S., \& Mao, J. (2020): Psychological health, sleep quality, and coping styles to stress facing the COVID-19 in Wuhan, China. Translational psychiatry, 10(1), $1-9$. https://doi.org/10.1038/s41398-020-00913-3.

- Geldsetzer, P. (2020): Knowledge and perceptions of COVID-19 among the general public in the United States and the United Kingdom: A crosssectional online survey. Annals of internal medicine. https://doi.org/10.7326/M20-0912.

- Goyal, K., Chauhan, P., Chhikara, K., Gupta, P., \& Singh, M. (2020): Fear of COVID 2019: First suicidal case in India! Asian journal of psychiatry, 49,

101989. doi: 10.1016/j.ajp.2020.101989.

- Ho, C., Chee, C., \& Ho, R. (2020): Mental health strategies to combat the psychological impact of COVID-19 beyond paranoia and panic. Ann Acad Med Singapore, 49(1), 1-3.
- Huang, Y., \& Zhao, N. (2020a): Generalized anxiety disorder, depressive symptoms and sleep quality during COVID-19 outbreak in China: a web-based cross-sectional survey. Psychiatry Research, 288, 112954. https://doi.org/10.1016/j.psychres.2020.112954.

- Huang, Y., \& Zhao, N. (2020b): Mental health burden for the public affected by the COVID-19 outbreak in China: Who will be the high-risk group?. Psychology, Health \& Medicine, 1-12. https://doi.org/10.1080/13548506.2020.1754438.

- Isah, M., Abdulsalam, M., Bello, A., Ibrahim, M., Usman, A., Nasir, A., Abdulkadir, B., Usman, A., Matazu, K., Sani, A., Aliu, M., Kabir, S., Shuaibu, A., \& Nass, S., (2020): Corona Virus Disease 2019 (COVID-19): Knowledge, attitudes, practices (KAP) and misconceptions in the general population of Katsina State, Nigeria. medRxiv. doi: https://doi.org/10.1101/2020.06.11.20127936.

- Jiménez-Pavón, D., Carbonell-Baeza, A., \& Lavie, C. (2020): Physical exercise as a therapy to fight against the mental and physical consequences of COVID-19 quarantine: Special focus in older people. Progress in cardiovascular diseases, 63(3): 386-388. doi: 10.1016/j.pcad.2020.03.009.

- Kar, S., Arafat, S., Kabir, R., Sharma, P., \& Saxena, S. (2020): Coping with mental health challenges during COVID-19. In Coronavirus Disease 2019 (COVID-19) (pp. 199-213). Springer, Singapore. https://doi.org/10.1007/978981-15-4814-7_16.

- Khesht-Masjedi, M.F., Omar, Z., \& Kafi, Masoleh, S.M. (2015): Psychometrics properties of the Persian version of Beck Anxiety Inventory in North of Iranian adolescents. International Journal of Educational and Psychological Researches, 1(2):145-153. DOI: $10.4103 / 2395-$ 2296.152233.

- Kretchy, I., Asiedu-Danso, M., \& Kretchy, J. (2020): Medication management and adherence during the COVID-19 pandemic: Perspectives and experiences from LMICs. Research in Social and Administrative Pharmacy. https://doi.org/10.1016/j.sapharm.2020.04.007.

- Labban, L., Thallaj, N., \& Labban, A. (2020): Assessing the level of awareness and knowledge of COVID 19 pandemic among Syrians. Arch Med, 12(2), 8.

- Lai, T., Tang, E., Fung, K., \& Li, K. (2020): Reply to "Does hand hygiene reduce SARS-CoV-2 transmission?". Graefe's Archive for Clinical and Experimental Ophthalmology, 1-1. https://doi.org/10.1007/s00417-020-04653-4.

- Li, Q., Guan, X., Wu, P., Wang, X., Zhou, L., Tong, Y., \& Xing, X. (2020): Early transmission 
dynamics in Wuhan, China, of novel coronavirusinfected pneumonia. New England Journal of Medicine. 382 (13): 1199-1207.

- Liu, X., \& Zhang, S. (2020): COVID-19: Face masks and human-to-human transmission. Influenza and Other Respiratory Viruses. https://doi.org/10.1111/irv.12740.

- Paparrigopoulos, T., Tzavara, C., Theleritis, C., Psarros, C., Soldatos, C., \& Tountas, Y. (2010): Insomnia and its correlates in a representative sample of the Greek population. BMC Public Health, 10: 531. doi: 10.1186/14712458-10-531.

- Reuben, R., Danladi, M., Saleh, D., \& Ejembi, P. (2020): Knowledge, attitudes and practices towards COVID-19: an epidemiological survey in North-Central Nigeria. Journal of community health, 1-14. https://doi.org/10.1007/s10900-02000881-1.

- Ripp, J., Peccoralo, L., \& Charney, D. (2020): Attending to the emotional well-being of the health care workforce in a New York City health system during the COVID-19 pandemic. Academic Medicine. doi: 10.1097/ACM.0000000000003414.

- Saqlain, M., Ahmed, A., Gulzar, A., Naz, S., Munir, M., Ahmed, Z., \& Kamran, S. (2020): Public knowledge and practices regarding COVID19: A cross-sectional survey from Pakistan. medRxiv. doi: https://doi.org/10.1101/2020.06.01.20119404.

- Silva, R., Macêdo, L., Santos, G., Aguiar, P., \& de Lyra, D. (2019): Pharmacist-participated medication review in different practice settings: service or intervention? An overview of systematic reviews. PloS one, 14(1), e0210312. http://dx.doi.org/10.1371/journal.pone.0210312.

- Wang, C., Pan, R., Wan, X., Tan, Y., Xu, L., Ho, C., \& Ho, R. (2020): Immediate psychological responses and associated factors during the initial stage of the 2019 coronavirus disease (COVID-19) epidemic among the general population in China. International journal of environmental research and public health, 17(5), 1729. https://doi.org/10.3390/ijerph17051729.

- WHO (2020): Clinical management of severe acute respiratory infection when COVID-19 is suspected, World Health Organization, Interim guidance V 1.2. 13 March 2020. https://www.who.int/publications-detail/clinicalmanagement-of-severe-acute-respiratory-infectionwhen-novel-coronavirus-(ncov)-infection-issuspected, Accessed on: 1/4/2020.

- Zaid, A., Barakat, M., Al-Qudah, R., Albetawi, S., \& Hammad, A. (2020): Knowledge and awareness of community toward COVID-19 in Jordan: A cross-sectional study. Systematic
Reviews in Pharmacy, 11(5), 624-631. DOI: $10.31838 / \mathrm{srp} .2020 .5 .87$.

- Zung, W. (2010): Validity of a Brazilian version of the Zung self-rating depression scale for the screening of depression in patients with Parkinson's disease. Parkinsonism \& Related Disorders, 16: 42-45. 